\title{
From leader to leadership: clinician managers and where to next?
}

\author{
Liz Fulop ${ }^{1,3}$ BArts(Hons), Cert Teaching, PhD, Professor - Health Management \\ Gary E. Day ${ }^{2}$ DHSM, MHM, BNurs, DipAppSc(Nursing Mgt), RN, EM, FCHSM, \\ Director - Organisational Development and Learning \\ ${ }^{1}$ Griffith Business School, Griffith University, Gold Coast Campus Southport, QLD 4215, Australia. \\ ${ }^{2}$ South Australian Department of Health, PO Box 287, Rundle Mall, SA 5000, Australia. \\ ${ }^{3}$ Corresponding author. Email: I.fulop@griffith.edu.au
}

\begin{abstract}
Individual clinician leadership is at the forefront of health reforms in Australia as well as overseas with many programs run by health departments (and hospitals) generally focus on the development of individual leaders. This paper argues, along with others, that leadership in the clinician management context cannot be understood from an individualistic approach alone. Clinician managers, especially in the ranks of doctors, are usually described as 'hybridprofessional managers' as well as reluctant leaders for whom most leadership theories do not easily apply. Their experiences of leadership development programs run by health departments both in Australia and internationally are likely to be based on an individual leader-focussed approach that is driving health care reforms. These approaches work from three key assumptions: (1) study and fix the person; (2) give them a position or title; and (3) make them responsible for results. Some would argue that the combination of these three approaches equates to heroic and transformational leadership. Several alternative approaches to leadership development are presented to illustrate how reforms in healthcare, and notably in hospitals, must incorporate alternative approaches, such as those based on collective and relational forms of leadership. This does not mean eschewing individual approaches to leadership but rather, thinking of them differently and making them more relevant to the daily experiences of clinician managers. We conclude by highlighting several significant challenges facing leadership development for clinician managers that arise from these considerations.
\end{abstract}

What is known about the topic? The professional development of clinical managers is topical in Australia at this time. Several professional development approaches emphasise the individual development of the clinician manager. The main emphasis of current programs is developing behaviours and traits in individual managers to make them better leaders. There is little empirical evidence of programs that are designed to strengthen a more distributed model of leadership in Australia. What does this paper add? At the very least a distributed leadership approach that emphasises relationship-based models should be considered as an alternative to professional development programs that concentrate on developing stronger skills in the individual clinical manager. Other relational-based approaches need to be explored to add to leadership development programs.

What are the implications for practice? Consideration needs to be given to increasing leadership capacity through professional development models that cultivate a shared or distributed leadership approach amongst its clinical leaders and in which the notion of relationship-based or relational-focussed approaches are incorporated.

The quality of leadership within health services, particularly in Australia, has been raised in several recent high-level health system reviews (p. 186) ${ }^{1}$ as a major factor contributing to high profile failures in patient care. In addressing the apparent leadership 'void' behind these failures, health departments throughout Australia, as elsewhere such as the UK, have turned their attention to leadership as a possible 'magic bullet' for solving the problems that bedevil health systems. Indeed, is often true that leadership is seen as a solution in and of itself for solving the quite complex systemic problems within healthcare. ${ }^{2,3}$ Many 'leadership' programs in health (and other areas from which health borrows) fall into what could be described as the 'sheep dipping' trade where select managers (cum leaders) are given training once or twice in their careers to become a leader. ${ }^{4}$ This 'sheep dipping' ethos in leader development means that many clinician managers rarely, if ever, become part of leadership programs that provide ongoing learning opportunities that connect to their daily experiences of leading clinical units. Moreover, many of these 'sheep trade' type programs are designed to address leadership issues from an individual perspective or what some term a 'leader development' or 'leader-centred' approach. ${ }^{4,5}$ The latter approaches focus on developing interpersonal competencies (styles, traits, etc.) of individual leaders (i.e. individual capacity building) to enhance their skills and effectiveness in order to build the human capital of the organisation..$^{5}$ One of the most popular and widely used leader centric approaches is transformational leadership or variants of it. ${ }^{4}$ 
Critics of leader development approaches point to the dangers of the self pre-occupation that emerges with the focus on the qualities, attributes and competencies of individual leaders helping to propagate a cult of 'self-development', 'selfawareness' and 'self-improvement' to solve significant organisational challenges that are usually beyond the remit of anyone person. ${ }^{4}$ The individualistic ethos also easily leads to heroic notions of leadership where the individual is often cast as a single, independent and discrete entity charged with the sole responsibility of addressing significant and complex systemwide challenges. ${ }^{4}$ This heroic notion of leadership reinforces some of the most pervasive problems of changing leadership practices in hospitals where emphasis on individual leadership persists despite the fact that '. . .leadership is only one aspect of 'managing' in healthcare (p. 469). ${ }^{2}$

Others argue that individual capacity building, in whatever shape or form it takes, is not really about leadership development, which is described by some as specifically referring to '...the development of collective processes and social capital in the organisation and beyond, involving relationships, networking, trust, and commitments' (p. $122^{4}$ ) as well as 'the appreciation of the social and political context and its implications for leadership styles and actions' (p. 325 $5^{5}$. The distinction between human (i.e. leader development) and social capital (i.e. leadership development) serves in the first instance to question the assumption that leadership is always the domain of one person per $s e^{6,7}$ and in particular, forces us to look beyond a single leader to leader-follower relations and to thinking about leadership as relationship based.

Relationship-based approaches to leadership (what is also sometimes referred to as 'new leadership') still include an individual approach to studying how social relations, especially between leaders and followers, develop through individual perceptions, cognition (e.g. self-concept), attributes and behaviours of social influence and exchange primarily to attain mutual goals in dyadic relationships between leader and members (or followers). These approaches stand in opposition to the heroic approaches to leader development, especially charismatic notions of leadership, but are still deemed as an 'entity' or individualistic approach because they still focus on the individual characteristics that leaders and followers bring to their interpersonal exchanges, so the 'internal' processes of individuals remains the focus. ${ }^{8}$ Some relationship-based approaches de-centre leadership and posit it as something occurring beyond leader-member dyads and thus extending to groups or larger collectivities. ${ }^{8}$ These approaches are also described as 'follower-centred' because they increasingly highlight collaborative forms of leadership, such as distributed, shared or team-based leadership, to name a few. ${ }^{4}$ It is our contention that relationship-based approaches rarely if ever inform leadership development programs for clinician managers or if they do, they are done so in a marginal way, usually in some 'throw-way' line about collaboration, shared leadership. Focussing on collective approaches is not new in heath care research, but translating research findings into leadership programs is much harder. ${ }^{9}$

A leadership perspective that does not start from an individualistic approach would offer even greater challenges for leadership development programs in healthcare. Such an approach, termed a 'relational perspective of leadership', in fact completely switches attention away from leaders as persons (with followers) to leadership as embedded in relationships (i.e. it is about relating and relatedness) and as a social influence process through which '...coordination (evolving social order) and change (e.g. new approaches, values, attitudes, behaviours and ideologies) are constructed and produced' (pp. 654-5). ${ }^{8}$ In opposition to entity approaches, the relational perspective of leadership views it as a process of organising in which all social constructions of leadership are continuously created and changed through language and communication (conversation, narratives, dialogue and multilogue) that are embedded in ongoing local, cultural and historical processes. The relational perspective of leadership treats the distinction between leader and manager or leader and follower as no longer critical because leadership is posited as an interactive process engaged in by participants who co-construct relational realities, that is, in a relational context where relational understanding is critical. ${ }^{7,8}$ Such an approach to leadership development means exploring how relational processes create the social dynamics that are critical to understanding leadership and by extension, how it is translated in a meaningful way into the daily practices and workings of particular groups of people. $^{8}$

The paper proceeds by considering leadership in the context of public hospitals and the challenges posed by this selectively complex and multi-faceted work place for clinician managers. It examines several individualistic approaches to leader development that are being utilised in the health field. The paper then discusses how leadership development could be rethought by introducing a stronger emphasis on relationship-based approaches to leadership into programs for clinician managers. The key aim is to see how a shift to a relational approach would change how we think about leadership development for clinician managers who, we argue, face some of the most challenging leadership situations found in any organisation. We propose that a relational shift would mean building on the work done in other fields of leadership research to better relate what we know to the experiences and challenges of clinician managers in their day to day work contexts. This approach is sensitive to the different contexts in which leadership is enacted across health settings.

\section{Clinician managers as reluctant leaders}

Clinicians, who hold positions such as directors, managers or heads of clinical units and remain in clinical practice working alongside other clinicians such as doctors, nurses and allied health professionals, are by definition 'clinician managers' in the context of the Australian healthcare system. If they work in teaching (or tertiary) hospitals they might also be active academics and researchers and these clinician managers represent the most extreme example of the 'hybrid professional-manager role' in hospitals. ${ }^{10,11}$ Clinician managers do not constitute a homogenous group in Australian public hospitals and in the case of doctors, the majority of them are staff specialists who are employed by the hospital, though their engagement in private practice can vary and there cases of Visiting Medical Officers (who are mainly in private practice) heading up clinical units. 
In terms of clinician managers, it is doctors who are traditionally singled out as being pivotal to healthcare reforms and to radical change within hospitals yet they are also recognised as the most difficult to integrate into the management systems of hospitals and are thus often targeted as the source of resistance to change. ${ }^{12,13}$ It is equally true that systems of administration in healthcare are not always supportive of the clinician manager role, especially doctors because of the myriad of problems these groups pose in terms of embracing management agendas and the predictable struggles that accompany moves to curb the jurisdictional domain of this highly professionalised group. ${ }^{10,14-16}$

It is also widely recognised that clinicians, and especially doctors, are pivotal to cost containment and rationalisation of services in hospitals and that their leadership is posited as essential to reforms that have proliferated health systems in OECD countries. ${ }^{12,13}$ Yet despite extensive health sector reforms in many countries, including Australia, these clinicians have managed to retain significant professional autonomy, and hence control, over the use, if not allocation, of resources in hospitals. ${ }^{10,14,17}$ Clinician managers, especially doctors, are often 'caught in the cross-fire' between calls to increase their role in relation to improving performance qua outcomes and targets across a range of areas while at the same time, still drawing significant autonomy from their professional roles. $^{18}$

The institutional context of the clinician manager is fraught with tensions and contradictions as well as time honoured power struggles. As has been noted in the Australian context, ${ }^{15}$ finding a leadership role for many clinicians is difficult when rather than seeing many professional groups, such as clinicians as partners, some hospital administrators fear and resent these groups treating them as 'amateur administrators.' By the same token, it has been observed that many health professionals blame professional, non-clinically trained administrators for all their problems and see them as the main obstacles to overcome in order to improve the management of hospitals and clinical practice. The complex hierarchies that health professionals work in, the intensely politicised nature of hospitals, the often poor alignment of responsibility, accountability and authority to perform one's job as a clinician manager, and the deeply embedded collegial system of professional health workers (leading to tribalism and calls for autonomy and independence), pose unique challenges for leadership in healthcare at all levels of management. $^{10,12,13,18,19}$

The unique bureaucratic nature of hospitals, and the dilemma of the purported multiple forms of leadership existing in them, pose significant challenges for all concerned. ${ }^{20}$ Professional leadership has its own form of resilience with many clinicians remaining more strongly influenced by their professional allegiances and obligations, including deeply entrenched collegial/peer affiliations. ${ }^{10,21}$ Some argue that professional leadership is de facto informal in many hospitals and that by creating clinician manager positions, hospital administrators have sought to actively integrate clinicians into systems of management and governance. They go on to suggest that hospitals are an example of what is termed a 'soft bureaucracy' because of their strong professional-medical forms of legitimation and control. Thus, hospitals have a hard and rigid exterior of managerially-based practices that symbolise what the public and external stakeholders expect of such institutions in terms of accountability, transparency and responsibility but on a day to day basis, their inner workings are characterised by loosely coupled practices and control systems that are based on the authority of clinicians. ${ }^{22}$ So despite the fact that there have been widespread changes in the health sector and the emergence of a new paradigm of professional-managerial relations based on the so-called 'responsibilisation' of medical autonomy, which is accompanied by the integration of medicine and management around new structures and management interventions, the actions of senior doctors still remain the most crucial factor in achieving health reforms at the hospital and clinical levels. ${ }^{9,17}$

When considering the context of the clinician managers, the framing must also account for the tensions and conflicts that shape notions of leadership as a professional process. ${ }^{23}$ For Gleeson and Knights this means acknowledging that professionally-based leadership comprises a cadre of highly qualified reluctant leaders who do not see management as a career goal but who work in systems that generally fail to engage them in ways that 'enrol their commitment and goodwill, and mobilise their willing expertise' (p. 65). ${ }^{23}$ They draw insights from the further education sector in the UK but believe that their approach to reluctant leaders has parallels in other sectors such as health. For others it also comes down to the fact that many of these managers are reluctant recruits who having stumbled into their roles, do not invest in the role as a career and therefore, are seen as lacking commitment and the management knowledge and skills that would merit giving them the professional autonomy they seek. ${ }^{18}$ Thus, they are portrayed as standing in opposition to non-clinician managers who are seen as the agents of managerialism and state policies, and in the case of doctors, this is said to also apply to other health professionals such as nurses who are cast as the vanguards of managerialist reforms within the ranks of clinician managers. ${ }^{12,18,24}$ The clinician manager is typified as someone who, as a clinician sees themselves as possessing a degree of supervisory autonomy (clinical freedom to apply their professional knowledge) but with minimal goal autonomy because of central targets and controls. Yet wearing their manager's 'hat', they often claim that they have neither professional nor goal autonomy, which is reflected in their lack of control over budgets and financial decisions. ${ }^{18}$ This suggests the clinician manager role has little to do with leadership, and if it did, we would only get woeful leaders.

Despite the above, the system needs clinicians on-side for much of the time for it to work and hence, the pressures to co-opt the best professionals, and often the informal leaders, into the ranks of clinician managers, in the hope of exerting a more managerially defined notion of leadership over their peers and colleagues. ${ }^{21}$ This co-opting or enrolment serves to institutionalise 'hard' governance with a 'soft' form of regulated professional autonomy. Despite this, it is also well recognised that leaders in healthcare at all levels are tightly bound by imposed policies and legislation and various other regimes of compliance that often makes the notion of leadership, as promulgated in many heroic approaches, difficult to apply. ${ }^{2,13}$ 


\section{Clinician manager and leader development}

Although there have been many studies examining health leadership, the focus on clinician management and leadership is still an under-researched area, especially where doctors head up clinical units and are caught in the middle-streams of management. Moreover, much of the recent research on health leadership that is influencing leadership development in Australia comes from the UK and falls into what has been termed a 'competency and capability approach' in which the principal aim is to catalogue key leadership qualities, attributes and capacities of individual leaders in order to provide better training and selection of health leaders to enhance performance related outcomes. ${ }^{7,11}$ This leader-centric approach is instrumental in its orientation and prescriptive in its purpose, and often devoid of any accounts of how these approaches can be universalised from one context and country to another. ${ }^{11,25}$ There is a strong normative flavour in much of this research and, although qualitative research is often used, it is used to create a categorisation, labelling and sorting approach to leadership studies. These approaches represent a dominant paradigm in the field and form the core of the individualistic approach that, although important to incorporate into leader development programs, rarely admits of other approaches that could more closely resonate with the lived experiences of clinician manager.

There are two approaches, the NHS Leadership Qualities Framework (LQF) and the Transformational Leadership Questionnaire (TLQ), which merit attention as they represent the current thinking at this point of time on leader development in mainstream health department programs and both derive from the UK. Underlying these two approaches is a strong competency agenda in which individual 'leadership' is seen as results-based so that individuals (in defined positions of leadership) are posited as critical drivers for achieving the outcomes of reform. The processes by which results are achieved or the role of followers in achieving them are largely incidental to the theories that inform the practice. $^{26}$

The LQF was developed by the Modernisation Agency Leadership Centre, which is part of the NHS and has had the adoption in Australia. The framework was initially developed as a competency model for Chief Executives and Directors within the NHS, but has since been extended to apply to all leadership levels in the service. The final framework was developed in consultation with all levels of leadership in the service using techniques such as focus groups and interviews.

The LQF comprises three clusters of leadership qualities considered to be important in the delivery of effective healthcare and the first comprises: Personal Qualities: self-belief, selfawareness, self-management, drive for improvement and personal integrity. The second cluster of qualities is more strategic in nature and is entitled: Setting Direction. Leadership qualities relating to direction-setting are: seizing the future, intellectual flexibility, broad scanning, political astuteness and drive for results. The third is called Delivering the Service, and comprises: leading change through people, holding to account, empowering others, effective and strategic influencing and collaborative working.

The LQF was designed to primarily explore and typify individual leadership behaviours and traits of the given leader.
Within each of the fifteen qualities, the NHS developed mastery 'steps' that highlight growth and development. The LQF has proved useful in identifying 'levels of achievement' and serves as a tool of assessment and notably, $360^{\circ}$ feedback, is used with other common strategies such as mentoring and 'sheep dipping' courses. However, the LQF does have several shortcomings. First, the framework does not adequately address several key leadership traits such as humour, courage and tenacity. Second, like several other frameworks, the LQF neatly encapsulates each of the 15 leadership qualities. In reality, there is an understanding that the delineation of these behaviours is rarely that clear cut. Finally, the LQF is designed for individual assessment and development of a leader's potential, not as a model that embraces team leadership behaviours. Although useful in individual development framework, the LQF does little to advance the concept of leadership as a shared, sense-making or giving experience, ${ }^{27,28}$ rather focussing on the impact or influence of one leader on their peers, subordinates and superiors. The LQF highlights 'personal' qualities and behaviours that may 'usefully articulate some of the things that a person does, or aspires to but it may (a) be a somewhat persecutory list of 'oughts' and (b) still do little to get effective leadership done' (p. 10). ${ }^{29}$

Another influential approach the leadership development comes from the work of Alimo-Metcalfe and AlbanMetcalfe $^{30-32}$ who have also had significant impact on leadership thinking in the UK NHS. Their research has focussed on transformational leadership studies in public sector organisations such as the NHS with staff being the main informants, thus focussing on 'nearby leadership' as distinct from distant leadership that typifies US research on the topic. ${ }^{33}$ The researchers took the view that transactional (associated with routine managerial tasks) and transformation leadership are both needed in effective leaders but that transformational leadership means something different in the UK context compared with many US studies because in the UK it means enabling others and doing transactional tasks in a transformational way. They claim their theory is about small ' $t$ ' transformational leadership and not the 'larger than life' heroics found in US studies. Their work also identified gender differences and questioned gendered constructs, such as empowerment, and sought to theorise the gender implications of the categorisations of leadership dimensions.

The TLQ was the main outcome of the research and was developed by Alimo-Metcalfe and Alban-Metcalfe ${ }^{30,32}$ for use in $360^{\circ}$ feedback and is one of the most well-known leadership tools in the UK. It incorporates 14 themes or characteristics organised into three overarching themes: (1) Leading and developing others; (2) Personal qualities; and (3) Leading the organisation. These are compared with performance-related outcomes as well. Coincidentally, political sensitivity and skills was omitted from the NHS dimensions as it was thought to be more relevant to local government contexts. As Fulop and Linstead ${ }^{34}$ note Alimo-Metcalf and Alban-Metcalf found that the leader as servant more aptly characterised how leadership in the NHS was framed by respondents in terms of managing change and enhancing organisational performance. Although their study also found vision to be important as a leadership quality, it was 
portrayed in terms of sculpting a shared vision and creating shared meaning and purpose, and involved other processes that help achieve a common purpose. They also found that in comparison to the heroic models of the USA, the UK version of transformational leadership emphasised connectedness and inclusiveness allowing them to conclude that there was a 'far greater sense of proximity, openness, humility, and 'vulnerability' in the UK approach to leadership...' (p. 63). ${ }^{32}$ They also noted that organisational, cultural and gender differences in their study might have accounted for differences found across the two countries. The findings are not surprising given that US approaches to transformational leadership typically see it as CEOs winning the hearts, souls and minds of followers so that work roles and self-identity become synonymous with successful performance reinforced by beliefs about self-acceptance and self-worth. Thus, typically self-sacrifice and exerting effort is dependent upon followers being completely subservient to the mission and vision of the organisation cum its leader. In turn, the leader has a moral responsibility to the followers and must be able to engage and inspire them at an emotional level. ${ }^{7}$

In the UK study, the importance of influence over followers was noted but the key to attaining it was by achieving a congruence between individual values, self-identity and dedication to the organisation and marrying, rather than subverting, these to task objectives and the mission of the organisation. Hence why Alimo-Metcalfe and Alban-Metcalfe describe their findings as more akin to servant leadership, where the focus is on the followers and organisational objectives are subordinate outcomes, which is the reversal of the US approach. ${ }^{32}$ Nonetheless, the literature questions the underlying rationale and usefulness of transformational leadership in the NHS, especially its focus on leader-centric assumptions relating to leaders empowering employees and performing morally and elevating acts in the context of highly regulated and risk averse situations in which most health leaders find themselves. ${ }^{2}$ They also note the confluence that occurs between the heroic and less heroic versions that is something that is often overlooked in many leadership development programs.

Although individual development is a necessary element of improved performance, none of the paradigms critiqued in this paper provide the 'magic' framework to both express and discuss the importance of the shared nature of leadership for clinical managers. We propose to give two versions of what a shared leadership experience might mean and the leadership development implications that follow. We draw one from the relationship-based approach and one from the relational perspective of leadership. Both reflect a move to a collective, de-centred approach to leadership, which we believe is critical to healthcare reforms. This echoes the views of several other observers of the health system who argue for leadership no longer being seen as a position in the hierarchy but a process that occurs throughout the organisation and beyond. ${ }^{2,11}$

\section{Discussion and conclusion}

A relationship-based approach to leadership that has some relevance to healthcare is the distributed leadership approach. Hence, in the search for a better leadership approach, there needs to be consideration of moving from heroic notions of leadership to post-heroic leadership paradigms. ${ }^{35}$ Research points to teamwork, participation, empowerment, risk taking and less control over others as examples of post-heroic leadership behaviours. ${ }^{35}$ Post-heroic leadership models emphasise "not in the individual agency of one, but the collaborative efforts of many' (p. 2). ${ }^{36}$ Although distributed leadership has been described in a variety of ways, the concept implies a social distribution of leadership where the leadership function is stretched over the work of several individuals and where the leadership task is accomplished through the interaction of multiple leaders. ${ }^{37}$ The literature supports this approach by suggesting a distributed leadership model promotes multiple groups of individuals, social distribution of the leadership function, and interdependency and shared responsibility. ${ }^{38}$ The concept of distributed leadership has merit in healthcare primarily because of the complex social and situational contexts that health leaders often encounter. Distributed leadership promotes inquiryoriented practice through collegial relationships ${ }^{38}$ and dynamic interdependence between individuals and groups. ${ }^{39}$ Despite this theoretical 'fit', this approach requires formal leadership positions to relinquish power to others. ${ }^{38}$

Research highlights other challenges in implementing a distributed leadership model within the existing 'command and control' bureaucratic organisational structures that are present in most major hierarchical organisations. ${ }^{40}$ These challenges include: a perceived notion of a managers' inability to initiate changes within the current structure; tension around influence and inclusion; broad-based buy in across the organisation; and trying to decentralise leadership while the formal structures become more centralised. Clearly, this approach needs the support of all levels of the organisation to ensure success but most of all it requires addressing the politics and power of authorisation that plagues leadership initiatives in hospitals. ${ }^{13}$ The panacea of multi-disciplinary teams or more lately, clinical networks, as a form of distributed leadership, is one recognised basis for research on leadership that will help to re-theorise leadership in the clinical contexts.

Nonetheless, the implications of this approach to leadership development are far-reaching for health how leadership development can be a shared responsibility, as manifesting in collective acts of leadership, as constituted in relationships other than those built on hierarchy, where social change processes can occur outside normal assumptions of command and control. ${ }^{8}$ Such an approach in healthcare requires a shift in research and leadership development to analysing the process of leadership under situations that are presented for general consumption as displaying persistent high ambiguity and complexity, as is the case in hospitals, where unclear goals, complicated hierarchical relations and systems of legitimation, are perennially being tested. $^{9,12,13}$

Turning to a relational perspective of leadership, we have argued earlier that the many clinician managers are often reluctant leaders and as such are unlikely to identify with notions of good or exemplary leadership that are promulgated in the dominant discourse of leadership. ${ }^{23,41}$ Thus, what is needed is an alternative discourse of leadership that is grounded in accounts of leadership work derived from situations that a clinician manager can identify with. This can begin with studies that draw on the experiences and sense making of middle managers at the level of meaning 
(their ideas, understandings and orientations) and the types of accounts (stories, narratives, etc.) of leadership this produces, including those of their followers, co-worker or colleagues. ${ }^{42}$ In the development of meaningful approaches to relational-based leadership education, ${ }^{37}$ there needs to be a move from "contextneutral, task generic templates designed to script leadership practice' to a 'need to deconstruct conscious and unconscious beliefs about leadership by reflecting on leadership practices through an investigation of lived routines and formally designed structures' (p. 10). ${ }^{40}$

Kelly et al. suggest that leadership work is a situated accomplishment and what we need to do is develop some sensitising cases and examples that will resonate with the experiences of managers who occupy similar positions (in their case it was high school principals and their senior managers in the UK). ${ }^{43}$ However, they say this will require presenting leadership work as 'the extraordinarisation of the mundane ${ }^{44,45}$ rather than the heroics of crisis management and organisational transformations that dominate leadership studies. They use an ethnographic study to distil what they consider to be the individual and collective accomplishments or activities that end up performing leadership for the benefit of others. ${ }^{43}$ In conducting their research they set out to identify what constitutes '. . . a good meeting; a good public presentation, a good staff briefing, a good presentation of accounts, and so forth. .. ${ }^{43}$ These are all activities that in fact dominate the day to day work of many clinician managers and present leadership opportunities across all contexts. Their study was framed in the context of the challenges posed by the discourse of new public management that has affected all areas of professional practice in the UK and certainly in Australia. They say that their research had nothing to do with revealing or uncovering secret or esoteric qualities of leadership but rather, they found that good leaders are competent and accomplished at two key things that are largely done through collective efforts of sense making. These they term the 'accumulation of organisational acumen' and the 'gambit of compliance', both terms derived from the work of Bittner. ${ }^{46}$ These terms have relevance when the focus of study shifts to observing how managers and their co-workers do leadership work through such things as the preparation and rehearsal of performances of effectiveness (such holding meetings and pre-meetings), how they work at the production of figures and facts, and how they work continuously and often in ingenious struggles with technology and data to produce convincing and 'authentic' performances of that work, to quote:

The 'gambit of compliance' ${ }^{46}$... requires that considerable experience and skill be used to legitimately accomplish this kind of work. Knowing which story to tell, which figures to use and which stakeholders to communicate to is an activity built up over time, through many repetitions (including success and failures) through which leadership work is refined and crafted into a stock of what Bittner has also termed 'organisational acumen'. (p. 195) ${ }^{43}$

They argue that both these accomplishments comprise the often taken-for-granted patterns of interactions and activities as well as relational skills that comprise everyday leadership work when it is no longer presented in an extraordinary way. This means seeing management and leadership as no longer separate but as what comes from sense making in these contexts. They also say that these entail the sort of experiences that are typical of '. . . been there done that' (p. 197) ${ }^{43}$ accounts that can be used to build a stock of knowledge to share and educate other managers in leadership work. Although organisational acumen is part of what entitles the leader to interpret rules and procedures to suit certain ends, it is also something that is distributed throughout an organisation. This work involves producing and mobilising convincing accounts of what is being done (e.g. achievements, financial status, performance, etc.) and this involves effort and collaboration as well as the manipulation of figures, stories, systems and technologies to get work done. This leads Kelly et al. to describe leadership as a pattern of activity that is summed up as 'leadership through the management of accounts' (hence relational and communicative) that must be seen to be done adequately by others (pp. 192-3). ${ }^{43}$ The gambit of compliance becomes a particular example of leadership through the management of accounts. These two concepts are extrapolated from the realm of doing professional leadership work and hence have parallels with the work of Gleeson and Knights $^{23}$ who found that leadership as a professional process comprise two contradictory processes. The first of this involves a high incidence of unintended consequences, ambiguity and wasted effort as well as the ensuing fatigue, low morale and de-professionalisation that is common in critiques of the new public management. The second they say entails innovative skills and practices being adopted by professionals in and against the new culture of audits and the like, and it is likely that these are the instances of what might be considered as leadership work. These are the parts of leadership that are not researched adequately and then translated into leadership development programs.

Although recent reviews of health services highlighted shortcomings in the leadership capacity and subsequently health departments responding with tailored leadership development programs, two questions must be asked: 'What kind of leaders are we developing?' and 'What approach are we using to ensure that the work of leadership gets done in ways that clinician managers can relate to?' The answers to these questions remain unclear as educators and researchers explore frameworks that will adequately support the leadership development of our clinical managers. Until this time, the provocation should be: Are we developing more robust individuals who are fated to fail because, as Albert Einstein so wisely observed: 'We cannot solve our problems with the same thinking we used when we created them' (p. 2612). ${ }^{47}$

\section{References}

1 Hindle D, Braithwaite J, Travaglia J, Iedema R. Patient safety: a comparative analysis of eight inquiries in six countries. Sydney: University of New South Wales; 2006.

2 Hewison A, Griffiths M. Leadership development in health care: a word of caution. J Health Organ Manag 2004; 18(6): 464-73. doi:10.1108/ 14777260410570018

3 Millward LJ, Bryan K. Clinical leadership in health care: a position statement. Int J Health Care Qual Assur Inc Leadersh Health Serv 2005; 18(2-3): xiii-xxv. 
4 Jackson BG, Parry KW. Enter stage right: The dramatic genre in leadership research. 17th Australian and New Zealand Academy of Management Conference. Surfing the waves of change: Management challenges-Management solutions; 2-5 December; Fremantle, WA; 2003.

5 Iles P, Preece D. Developing leaders or developing leadership? The Academy of Chief Executives' programmes in the north east of England. Leadersh 2006; 2(3): 317-40. doi:10.1177/174271500606 6024

6 Bailey C, Burr J. Luck, Legacy or Leadership: The Contribution of Leadership to Sustained Organisational Success in NHS Trusts: Interim report. Cranfield, UK: The NHS Leadership Center and Cranfield School of Management; 2005.

7 Bolden R, Wood M, Gosling J. Is the NHS Leadership Qualities Framework missing the wood from the trees? In: Casebeer AL, Harrison, A, Mark, AL, editors. Innovations in Health Care: A Reality Check. Houndsmill: Palgrave; 2006.

8 Uhl-Bien M. Relational Leadership Theory: exploring the social processes or leadership and organizing. Leadersh $Q$ 2006; 17: 654-76. doi:10.1016/j.leaqua.2006.10.007

9 Denis J-L, Langley A, Cazale L. Leadership and strategic change under ambiguity. Organ Stud 1996; 17(4): 673-99. doi:10.1177/017084069 601700406

10 Kitchener M. The 'bureaucratization' of professional roles: the case of clinical directors in UK hospitals. Organization 2000; 7(1): 129-54. doi: $10.1177 / 135050840071007$

11 Smith D, Eades E. The competent medical manager: issues in the management of healthcare professionals. Clinician in Management 2003; 12(1): 11-20.

12 Degeling P, Carr A. Leadership for the systemization of health care: the unaddressed issue in health care reform. J Health Organ Manag 2004; 18(6): 399-414. doi:10.1108/14777260410569975

13 Degeling P, Maxwell S, Kennedy J, Coyle B. Medicine, management and modernisation: a 'danse macabre'? BMJ 2003; 326: 649-52. Available at http://www.bmj.com/cgi/reprint/326/7390/649 [verified 26 January 2009].

14 Doolin B. Enterprise discourse, professional identity and the organizational control of hospital clinicians. Organ Stud 2002; 23(3): 369-90. doi:10.1177/0170840602233003

15 Eastman CJ, Fulop L. Management for clinicians or the case of 'bringing the mountain to Mohammed. Int J Prod Econ 1997; 52: 15-30. doi:10.1016/S0925-5273(96)00092-8

16 Scott I, Stevens S, Von Hellens L, Iselin G. Engaging clinical leaders in integrating research and practice: first report. National Institute of Clinical Studies, Griffith University and Princess Alexandra Hospital; 2003. [Confidential report - not for circulation]

17 Dent M. Managing doctors and saving a hospital: Irony, rhetoric and actor networks. Organization 2003; 10(1): 107-27. doi:10.1177/13505084 03010001379

18 Hoque K, Davis S, Humphreys M. Freedom to what you are told: Senior management team autonomy in an NHS trust. Public Adm 2004; 82(2): 355-75. doi:10.1111/j.0033-3298.2004.00398.x

19 McDermott R, Callanan I, Buttimer A. Involving Irish clinicians in hospital management roles - towards a functional integration model. Clinician in Management 2002; 11(1): 37-46.

20 Dopson S, Mark AL. Leading Health Care Organizations. London: Palgrave Macmillan; 2003.

21 Sheaff R, Rogers A, Pickard S, Marsha M, Campbell S, Roland S, et al. Medical leadership in English primary care networks. In: Dopson S, Mark AL, editors. Leading Health Care Organizations. London: Palgrave Macmillan; 2003.

22 Clegg SR, Courpasson D, Phillips N. Power and organizations. London: Sage; 2006
23 Gleeson D, Knights D. Reluctant leaders: an analysis of middle managers' perceptions of leadership in further education in England. Leadersh 2008; 4(1): 49-72. doi:10.1177/1742715007085769

24 Carr A, Degeling P, Winters M, Carr A, Degeling P, Winters M. Physicians heal thyself: the results of an empirical study into stress amongst medical clinicians and other occupational subgroups during a period of organization change in a hospital system. 21st Standing Conference on Organizational Symbolism: Organisational wellness: mens sana in corporate sano; 9-12 July, University of Cambridge; 2003.

25 Hamlin RG. A study and comparative analysis of managerial and leadership effectiveness in the National Health Service: an empirical factor analytic study within an NHS Trust hospital. Health Serv Manage 2002; 15: 245-63. doi:10.1258/095148402320589046

26 Grint K. The arts of leadership. Oxford: Oxford University Press; 2000.

27 Maitlis S. The social process of organizational sensemaking. Acad Manage J 2005; 48(1): 21-49. doi:10.2307/20159639

28 Maitlis S, Lawrence D. Triggers and enablers of sensegiving in organizations. Acad Manage J 2007; 50(1): 57-84. doi:10.2307/ 20159841

29 Wood M, Gosling J. Is the NHS Leadership Qualities Framework missing the wood for the trees? 2006. Available at http://www.leadership-studies. com/documents/WP1.pdf [verified 20 February 2009].

30 Alimo-Metcalfe B, Alban-Metcalfe J. The development of a new Transformational Leadership Questionnaire. J Occup Organ Psychol 2001; 74: 1-27. doi:10.1348/096317901167208

31 Alimo-Metcalfe B, Lawler J. Leadership development in UK companies at the beginning of the twenty-first century: lessons for the NHS. J Manag Med 2001; 15(5): 387-404. doi:10.1108/EUM00000 00006185

32 Alimo-Metcalfe B, Alban-Metcalfe J. Leadership: the time for a new direction? Leadersh 2005; 1(1): 51-71. doi:10.1177/1742715005049351

33 Powell S. Spotlight: interview with Beverley Alimo-Metcalfe. J Health Organ Manag 2004; 18(6): 393-8. doi:10.1108/14777260410569966

34 Fulop L, Linstead S. Leadership and leading. In: Linstead S, Fulop L, Lilley S, editors. Management and Organization: A Critical Text. 2nd edn. Houndsmills: Palgrave Macmillan; 2009.

35 Odura GKT. Distributed Leadership' in schools: what English headteachers say about 'pull' and 'push' factors. British Educational Research Association Annual Conference; 16-18 September, University of Manchester; 2004.

36 Johnson SM. The misguided search for heroic leadership: A brief article. School Administrator 1997; (February). Available at http://findarticles. com/p/articles/mi_m0JSD/is_2_54/ai_77382130 [verified 20 November 2008].

37 Spillane J. Distributed leadership. San Franscisco: Jossey-Bass; 2006.

38 Harris A. Teacher leadership as distributed leadership: heresy, fantasy or possibility? Sch Leadersh Manage 2003; 23(3): 313-24. doi:10.1080 1363243032000112801

39 Greenfield T. Theory about organization: new perspective and its implications for schools. In: Greenfield $\mathrm{T}$, Ribbins $\mathrm{P}$, editors. Greenfield on Education Administration: Towards a Human Science. Routledge; 1993

40 Wright LL. Merits and limitations of distributed leadership: experiences and understandings of school principals. Can J Educ Adm Policy 2008; 69. Available at http://www.umanitoba.ca/publications/cjeap/articles/ wright.html [verified 15 November 2008].

41 Collins JC. Level 5 leadership: the triumph of humility and fierce resolve. Harv Bus Rev 2001; 79(1): 66-76.

42 Alvesson M, Sveningsson S. Good visions, bad micro-management and ugly ambiguity: Contradictions of (non-) leadership in knowledge intensive organizations. Organ Stud 2003; 24(6): 961-88. doi:10.1177/ 0170840603024006007 
43 Kelly S, Iszatt White M, Martin D, Rouncefield M. Leadership refrains: patterns of leadership. Leadersh 2006; 2(2): 181-201. doi:10.1177/ 1742715006062934

44 Alvesson M, Sveningsson S. Managers doing leadership: the extraordinarization of the mundane. Hum Relat 2003; 56(12): 1435-59. doi:10.1177/00187267035612001

45 Alvesson M, Sveningsson S. The great disappearing act: difficulties in doing "leadership". Leadersh Q 2003; 14: 359-81. doi:10.1016/S10489843(03)00031-6
46 Bittner E. The concept of organization. Soc Res 1965; 32(3): 239-55.

47 Owen H. Zero harm: a target for error management in anaesthesia. Bulletin of the Royal College of Anaesthetists 2008; 51(September). Available at http://www.rcoa.ac.uk/docs/Bulletin51.pdf\#page $=21$ [verified 21 October 2008].

Manuscript received 27 March 2009, accepted 10 August 2009 